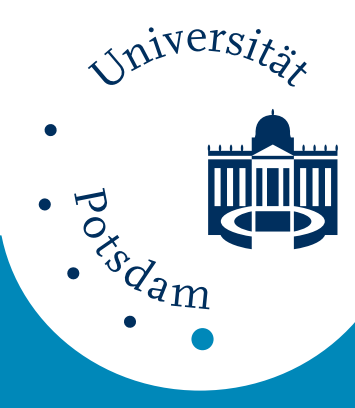

Universität Potsdam

Yuji Watanabe, Gerhard P. Püschel, Andreas Gardemann, Kurt Jungermann

\title{
Presinusoidal and proximal intrasinusoidal confluence of hepatic artery and portal vein in rat liver : functional evidence by orthograde and retrograde bivascular perfusion
}

first published in:

Hepatology. - 19 (1994), 5, pp. 1198-1207

ISSN 0270-9139

Postprint published at the Institutional Repository of the

Potsdam University:

In: Postprints der Universität Potsdam :

Mathematisch-Naturwissenschaftliche Reihe ; 67

http://opus.kobv.de/ubp/volltexte/2008/1670/

http://nbn-resolving.de/urn:nbn:de:kobv:517-opus-16702

Postprints der Universität Potsdam

Mathematisch-Naturwissenschaftliche Reihe ; 67 


\title{
Presinusoidal and Proximal Intrasinusoidal Confluence of Hepatic Artery and Portal Vein in Rat Liver: Functional Evidence by Orthograde and Retrograde Bivascular Perfusion
}

\author{
Yudi Watanabe, Gerhard P, PÜSChEL, ANDREas GaRdemann and KuRT JUnGeRmanN \\ Institut für Biochemie und Molekulare Zellbiologie, Georg-August-Universität, Humboldtallee 23, D-37073 \\ Göttingen, Germany
}

\begin{abstract}
The site of confluence of the artery and the portal vein in the liver still appears to be controversial. Anatomical studies suggested a presinusoidal or an intrasinusoidal confluence in the first, second or even final third of the sinusoids. The objective of this investigation was to study the problem with functional biochemical techniques. Rat livers were perfused through the hepatic artery and simultaneously either in the orthograde direction from the portal vein to the hepatic vein or in the retrograde direction from the hepatic vein to the portal vein. Arterial flow was linearly dependent on arterial pressure between $70 \mathrm{~cm}$ $\mathrm{H}_{2} \mathrm{O}$ and $120 \mathrm{~cm} \mathrm{H}_{2} \mathrm{O}$ at a constant portal or hepatovenous pressure of $18 \mathrm{~cm} \mathrm{H}_{2} \mathrm{O}$. An arterial pressure of $100 \mathrm{~cm} \mathrm{H}_{2} \mathrm{O}$ was required for the maintenance of a homogeneous orthograde perfusion of the whole parenchyma and of a physiologic ratio of arterial to portal flow of about $1: 3$. Glucagon was infused either through the artery or the portal vein and hepatic vein, respectively, to a submaximally effective "calculated" sinusoidal concentration after mixing of $0.1 \mathrm{nmol} / \mathrm{L}$. During orthograde perfusions, arterial and portal glucagon caused the same increases in glucose output. Yet during retrograde perfusions, hepatovenous glucagon elicited metabolic alterations equal to those in orthograde perfusions, whereas arterial glucagon effected changes strongly reduced to between $10 \%$ and $50 \%$. Arterially infused trypan blue was distributed homogeneously in the parenchyma during orthograde perfusions, whereas it reached clearly smaller areas of parenchyma during retrograde perfusions. Finally, arterially applied acridine orange was taken up by all periportal hepatocytes in the proximal half of the acinus during orthograde perfusions but only by a much smaller portion of periportal cells in the proximal third of the acinus during retrograde perfusions. These findings suggest that in rat liver, the
\end{abstract}

This study was supported by the Deutsche Forschungsgemeinschaft, D-53170 Bonn-Bad Godesberg, through the Sonderforschungsbereich 236, D-37075 Göttingen, and the Fond der Chemie, D-60329 Frankfurt.

Address reprint requests to: Kurt Jungermann, Institut für Biochemie, Georg-August-Universität, Humboldtallee 23, D-37073 Göttingen. hepatic artery and the portal vein mix before and within the first third of the sinusoids, rather than in the middle or even last third. (HePATOLOGY 1994;19: 1198-1207.)

The liver is supplied with blood by two vessels, the hepatic artery and the portal vein. The isolated liver perfused monovascularly only through the portal vein has been and still is an important experimental model for the study of liver metabolism and its hormonal and nervous regulation. The model is unphysiologic in that it excludes possible differences in substrate supply and hormone input from the hepatic artery and the portal vein. Therefore a perfusion system was established, which allows the simultaneous perfusion of rat liver through the hepatic artery with high pressure $(100 \mathrm{~cm}$ $\mathrm{H}_{2} \mathrm{O} \approx 80 \mathrm{~mm} \mathrm{Hg}$ ) and about $25 \%$ of total flow and through the portal vein with low pressure $(18 \mathrm{~cm}$ $\mathrm{H}_{2} \mathrm{O} \approx 14 \mathrm{~mm} \mathrm{Hg}$ ) and about $75 \%$ of total flow $(1,2)$. For studies of possible different uses of substrates applied arterially or portally and of different actions of hormones delivered arterially or portally, it is mandatory to know whether the hepatic artery and the portal vein supply the same amount of tissue (i.e., whether they mix before or after entering the sinusoids).

Surprisingly, the anatomy of the vascular supply of the liver parenchyma is still controversial. Anatomical studies with different species used various techniques such as serial sections taken after the vessels were injected with dyes $[3,4]$, scanning electron microscopy of microvascular casts [5-9], microradiography [10] and transillumination microphotography $[11,12]$. In these investigations different hepatic arterial terminations were observed. Arterioles were found (1) to terminate in the terminal portal vein and in the first third of the sinusoids (zone 1) equally in rabbits [10], more frequently in the terminal portal vein in rats $[5,9]$ or more frequently, almost exclusively in the sinusoids in hamster and human beings [9], as well as in rats, mice, pigs and rabbits $[11,12]$; (2) to end in the first and middle third of the sinusoids in pigs and monkeys $[8,13]$; and (3) to penetrate deeply into the sinusoids, also ending in the middle and last third in rodents $[3,4,6,7]$ (Fig. 1). 
It was the objective of this investigation to study the vascular supply of the liver parenchyma with functional biochemical techniques. In the arterially and portally perfused rat liver, glucagon infused through the artery clearly increased glucose output more strongly and trypan blue applied through the artery clearly reached a greater mass of parenchyma during orthograde perfusion from the portal vein to the hepatic vein than during retrograde perfusion from the hepatic vein to the portal vein. Moreover, acridine orange delivered through the artery was taken up by all hepatocytes in the periportal half of the acinus during orthograde perfusion but clearly by fewer cells in the proximal periportal third of the acinus during retrograde perfusion. These findings allow the conclusion that in rat liver the hepatic artery and the portal vein mix before and within the first third of the sinusoids.

\section{MATERIALS AND METHODS}

Materials. All chemicals were reagent grade and from commercial sources. Enzymes were purchased from Boehringer Mannheim GmbH (Mannheim, Germany) and glucagon from Serva Feinbiochemica $\mathrm{GmbH} \&$ Co. (Heidelberg, Germany).

Animals. Male Wistar rats (180 to $220 \mathrm{gm}$ ) were obtained from Harlan-Winkelmann (Borchen, Germany). At least 1 wk before the experiment, they were subjected to a 12-hr daynight rhythm (7 AM to $7 \mathrm{PM}$ light period) with free access to food (standard diet R of Ssniff; Spezialdiäten GmbH, Soest, Germany). All experiments were started at about 9:00 AM. Animals were anesthetized by intraperitoneal injection of pentobarbital (60 $\mathrm{mg} / \mathrm{kg}$ body wt).

Liver Perfusion. The liver was perfused in situ without recirculation in a $37^{\circ} \mathrm{C}$ cabinet through the hepatic artery with "high pressure" ranging from $70 \mathrm{~cm} \mathrm{H} \mathrm{H}_{2} \mathrm{O}(\approx 52 \mathrm{~mm} \mathrm{Hg} ; 6.9$ $\mathrm{kPa})$ to $120 \mathrm{~cm} \mathrm{H} \mathrm{H}_{2} \mathrm{O}(\approx 90 \mathrm{~mm} \mathrm{Hg} ; 11.8 \mathrm{kPa}$ ), which provided $15 \%$ to $30 \%$ of flow, and simultaneously either through the portal vein in the orthograde direction to the hepatic vein or through the hepatic vein in the retrograde direction to the portal vein, each with "low pressure" of about $18 \mathrm{~cm} \mathrm{H}_{2} \mathrm{O}$ ( $\approx 14 \mathrm{~mm} \mathrm{Hg} ; 1.8 \mathrm{kPa}$ ), which provided $70 \%$ to $85 \%$ of flow. The preparation technique used in the retrograde perfusion is basically the same as that described in detail previously for the orthograde perfusion $[1,2]$, except that bilaterally the renal and adrenal arteries and veins, and supradiaphragmatically the aorta and vena cava inferior were all ligated to prevent leakage caused by the unphysiological circulation. In the orthograde perfusion the hepatovenous outflow was positioned at $1 \mathrm{~cm}$ below the liver, whereas in the retrograde perfusion the portal outflow was positioned at $3 \mathrm{~cm}$ below the organ in order to maintain similar flow rates without swelling of the liver. In addition, the diameter of the portal catheter was large enough to prevent any restriction of the portal outflow during retrograde perfusions. Perfusion pressure and thus flow in the arterial and portal or hepatovenous inflow, respectively, were varied as indicated, with the total flow maintained in the range of $3.6 \mathrm{ml} \cdot \mathrm{min}^{-1} \cdot \mathrm{gm} \mathrm{liver}{ }^{-1}$. The basic perfusion medium was a Krebs-Henseleit bicarbonate buffer, which contained $5 \mathrm{mmol} / \mathrm{L}$ glucose, $2 \mathrm{mmol} / \mathrm{L}$ lactate and $0.2 \mathrm{mmol} / \mathrm{L}$ pyruvate and was equilibrated with a gas mixture of $95 \%$ ( $\mathrm{vol} / \mathrm{vol}$ ) oxygen and $5 \%$ (vol/vol) carbon dioxide. The effluent medium was collected after a preperfusion period of $30 \mathrm{~min}$ and cooled on ice. Glucagon was infused for 5 min only once as the first stimulus in each experiment from 40 to $45 \mathrm{~min}$ through either

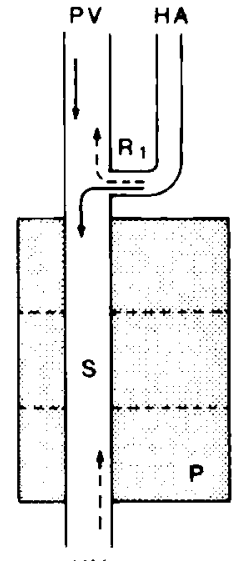

HV

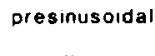

contivence

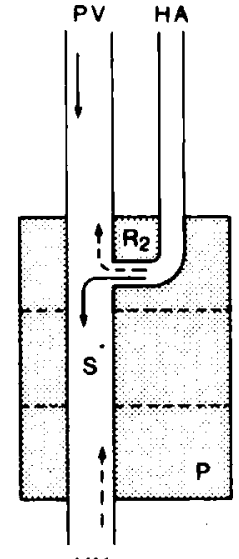

HV

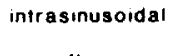

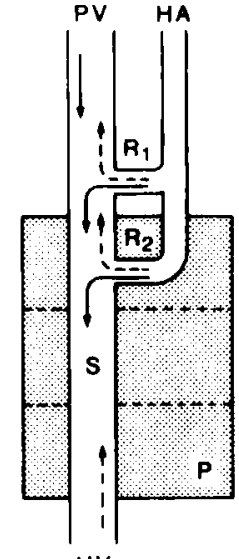

HV sinusoidal

confluence

FIG. 1. Different models of the vascular supply of the liver. $H A$, hepatic artery; $H V$, hepatic vein; $P V$, portal vein; $S$, sinusoid; $P$, parenchyma; $R_{1}$, arterial resistance site at the confluence with the terminal portal vein; $R_{2}$, = arterial resistance site at the confluence with the sinusoids. It is assumed that $R_{1}$ is smaller than $R_{2}$. Orthograde perfusion is represented by solid lines with arrows; retrograde perfusion is represented by broken lines with arrows. Presinusoidal confluence: Arterioles terminate into the terminal portal vein and into the beginning of the sinusoids $(5,9-11)$. The artery and portal vein supply the same amount of tissue. During orthograde perfusion all acini in their total length are reached from the artery provided that the arterial pressure can overcome the maximal value of $\mathrm{R}_{1}$; during retrograde perfusion no acini are reached from the artery. Intrasinusoidal confluence: Arterioles terminate into the first and middle $[8,12]$ or even into the middle and last third of the sinusoids $(3,4,6,7)$; only the proximal intrasinusoidal confluence is shown. The artery supplies less tissue than the portal vein. During orthograde perfusion all hepatocytes except in the proximal first (and second) third of the sinusoids are reached from the artery provided that the arterial pressure can overcome the maximal value of $R_{2}$; during retrograde perfusion only hepatocytes in the first (and second) third of the sinusoids are reached from the artery. Presinusoidal and intrasinusoidal confluence: Arterioles terminate into the terminal portal vein and into the sinusoids. During orthograde perfusion all hepatocytes are reached from the artery as long as the arterial pressure can overcome $\mathbf{R}_{1}$; during retrograde perfusion proximal hepatocytes are reached from the artery as long as the arterial pressure can overcome $R_{2}$, but no hepatocytes are reached if the arterial pressure cannot overcome $R_{2}$

the hepatic artery, the portal vein or the hepatic vein with the use of a microinfusion pump to reach a final calculated concentration in the sinusoids after mixing of $0.1 \mathrm{nmol} / \mathrm{L}$. The calculation was based on the ratio of arterial to portal or hepatovenous inflow: the portal (orthograde) or hepatovenous (retrograde) inflow concentration was diluted (e.g., to two thirds) by the arterial inflow, and conversely the arterial inflow concentration was diluted (e.g., to one third) by the portal inflow. Thus the concentration in the portal or hepatovenous inflow was $0.15 \mathrm{nmol} / \mathrm{L}$ and in the arterial inflow, $0.3 \mathrm{nmol} / \mathrm{L}$. The actual average concentration reached in the sinusoids before and after mixing depends on the location of the site of confluence (Fig. 1) and the rate of glucagon degradation. 


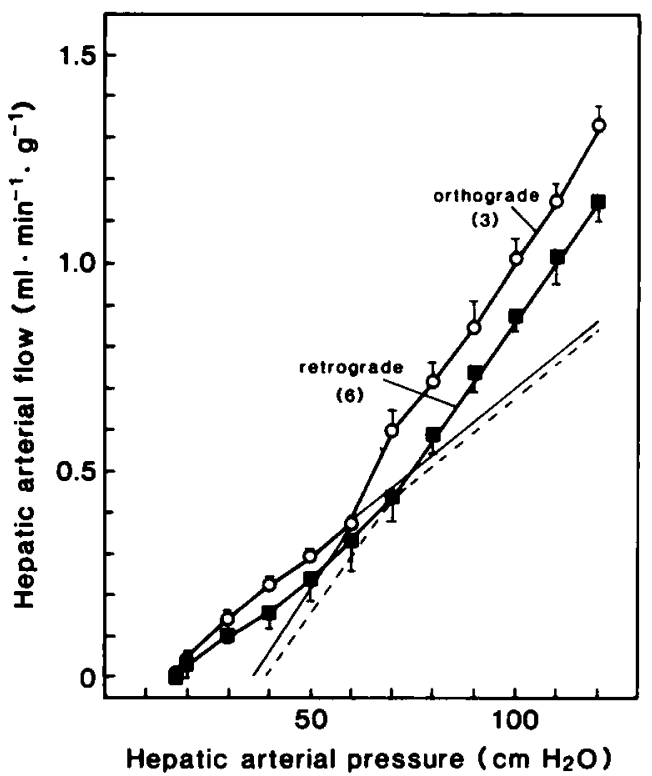

FIG. 2. Arterial flow as a function of arterial pressure in rat liver perfused through the artery and the portal or hepatic vein. The liver was perfused with Krebs-Henseleit buffer containing $5 \mathrm{mmol} / \mathrm{L}$ glucose, $2 \mathrm{mmol} / \mathrm{L}$ lactate and $0.2 \mathrm{mmol} / \mathrm{L}$ pyruvate in the orthograde direction from the artery and the portal vein to the hepatic vein or in the retrograde direction from the artery and the vena cava and then from the hepatic vein to the portal vein. The pressure in the portal or hepatovenous inflow was held constant at $18 \mathrm{~cm} \mathrm{H}_{2} \mathrm{O}$; the pressure in the artery was varied stepwise every $2 \mathrm{~min}$ from $120 \mathrm{~cm} \mathrm{H}_{2} \mathrm{O}$ down to zero. Arterial flow was determined as described in the Materials and Methods section during the last $30 \mathrm{sec}$ of the 2 -min periods. The solid lines represent the extrapolations of the two halves of the orthograde perfusion curves; the dashed lines represent the extrapolations of the retrograde perfusion curves.

Determination of Metabolic Rates and Perfusion Flow. Glucose was measured by means of a standard enzymatic technique with glucose dehydrogenase [14]. Total perfusion flow was quantitated by fractionating the effluent into calibrated tubes. Portal flow during orthograde perfusions or hepatovenous flow during retrograde perfusion was measured with a SMS-302 electromagnetic flowmeter (PPG Hellige GmbH, Freiburg, Germany) placed into the portal or hepatovenous inflow, respectively, and arterial flow was obtained as the difference between total and portal or hepatovenous flow, respectively.

Visualization of Microcirculation. Trypan blue was infused into the hepatic artery or the portal and hepatic veins, respectively, to a final concentration of about $0.2 \%$ in separate experiments [15]. Distribution of the dye was monitored by inspection of the liver surface and of cross sections; photographs were taken as indicated in the figure legends. Acridine orange was applied through the artery or the portal and hepatic veins, respectively, to a final concentration of about $120 \mu \mathrm{mol} / \mathrm{L}$ in separate experiments. The uptake of the compound into hepatocytes was studied in $10 \mu \mathrm{m}$ cryostat sections of the liver [16], which were prepared from liver samples removed $5 \mathrm{~min}$ after starting the perfusion with 120 $\mu \mathrm{mol} / \mathrm{L}$ acridine orange and immediately frozen in isopentane cooled in liquid nitrogen.

\section{RESULTS}

Rationale of the Study. If the hepatic artery and the portal vein mix at a presinusoidal site (Fig. 1, left), a compound applied through the artery will reach the entire parenchyma during orthograde perfusions, but it will not reach the parenchyma at all during retrograde perfusions. Therefore the transit time of the arterially administered compound will be longer during orthograde perfusions and shorter during retrograde perfusions. Moreover, in orthograde perfusions an arterially infused hormone, such as glucagon, will cause a defined metabolic alteration; an arterially supplied dye, such as trypan blue, will stain the liver homogeneously and an arterially added substrate such as acridine orange will be taken up by all proximal hepatocytes. However, in retrograde perfusions the hormone will be ineffective, the dye will not stain the liver at all and a substrate will pass without uptake.

If the hepatic artery and the portal vein mix at an intrasinusoidal site (Fig. 1, middle), for example, at the end of the first third of the sinusoid, a substance entering through the artery will reach only a portion of the parenchyma (i.e., the second and final thirds during orthograde perfusion and the first third during retrograde perfusion). The situation can be illustrated with three examples. (1) An arterially infused hormone will cause a defined metabolic effect, which will be greater by twofold during orthograde perfusion than during retrograde perfusion, provided that the hormone is equally effective at all sites of the sinusoid. (2) An arterially supplied dye will stain the liver nonhomogeneously, to a greater extent during orthograde perfusion and to a lesser extent during retrograde perfusion. (3) An arterially added substrate will be taken up by hepatocytes at least in the middle third of the sinusoid during orthograde perfusion and in the first third during retrograde perfusion.

If the hepatic artery and the portal vein mix both at a presinusoidal site and an intrasinusoidal site (Fig. 1, right), the pattern of responses will be the complex combination of the two "simple" anatomic situations.

Orthograde and Retrograde Bivascular Liver Perfusion. Rat livers were perfused in situ without recirculation through the artery and the portal vein in the orthograde direction or through the artery and the vena cava and then through the hepatic vein in the retrograde direction. At constant portal or vena cava pressure of 18 $\mathrm{cm}_{2} \mathrm{O}$, arterial flow was linearly dependent on arterial pressure between $120 \mathrm{~cm} \mathrm{H}_{2} \mathrm{O}$ and about 60 to $70 \mathrm{~cm}$ $\mathrm{H}_{2} \mathrm{O}$; at the same arterial pressure arterial flow was slightly lower during retrograde perfusion than during orthograde perfusions (Fig. 2). The break in the proportionality between arterial flow and arterial pressure at 60 to $70 \mathrm{~cm} \mathrm{H}_{2} \mathrm{O}$ indicates that it is important to keep the arterial pressure at least greater than this critical value in the isolated bivascularly perfused rat liver. An arterial pressure of $100 \mathrm{~cm} \mathrm{H} \mathrm{H}_{2} \mathrm{O}$ was required to maintain a homogeneous orthograde perfusion of the whole parenchyma and a physiological ratio of arterial to portal flow of about $1: 3$ (see below).

In a first series of experiments an arterial pressure of $100 \mathrm{~cm} \mathrm{H}_{2} \mathrm{O}$ and a portal or hepatovenous pressure of 18 $\mathrm{cm} \mathrm{H}_{2} \mathrm{O}$ were maintained (Fig. 3 ). Throughout the whole experiment the flow could be held constant with a 

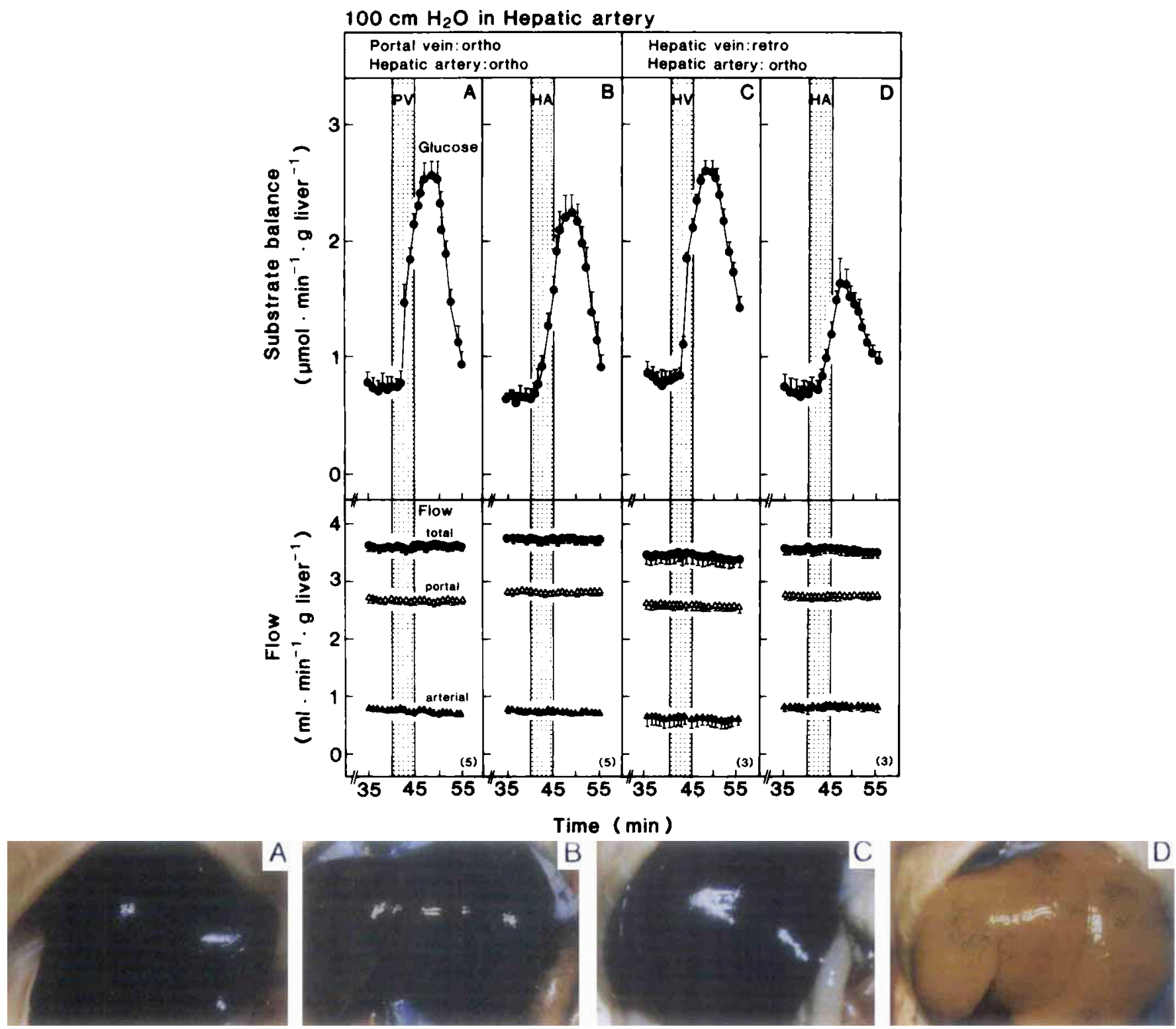

FIG. 3. Glucose balance, flow and intrahepatic distribution of trypan blue visualized at the surface after glucagon infusion in rat liver perfused through the artery at a pressure of $100 \mathrm{~cm} \mathrm{H} \mathrm{H}_{2} \mathrm{O}$ and through the portal vein or hepatic vein, respectively, at a pressure of $18 \mathrm{~cm} \mathrm{H}_{2} \mathrm{O}$. The liver was perfused with Krebs-Henseleit buffer containing $5 \mathrm{mmol} / \mathrm{L}$ glucose, $2 \mathrm{mmol} / \mathrm{L}$ lacate and $0.2 \mathrm{mmol} / \mathrm{L}$ pyruvate in the orthograde direction from the artery and the portal vein to the hepatic vein or in the retrograde direction from the artery and the vena cava and then from the hepatic vein to the portal vein (cf. Fig. 1 and the Materials and Methods section). Glucagon was infused only once per experiment for 5 min through the artery (B, D), portal vein (A) or hepatic vein (C) as indicated to a final calculated sinusoidal concentration of $0.1 \mathrm{nmol} / \mathrm{L}$ (graphs, top). Trypan blue was infused for $1 \mathrm{~min}$ through the artery (B, D) or the portal vein (A) or hepatic vein (C) to a final sinusoidal concentration of $0.2 \% 15$ min after the termination of glucagon infusion (photographs, bottom). Substrate balance during orthograde perfusion is defined by (concentration in hepatic vein in micromoles $\times \mathrm{ml}^{-1} \times$ flow in $\mathrm{ml} \times \mathrm{min}^{-1} \times \mathrm{gm}^{-1}$ ) - (concentration in portal vein in micromoles $\times$

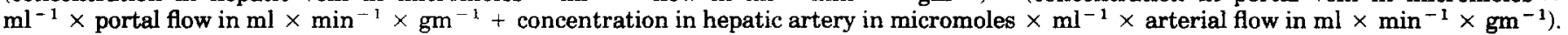
In this formula during retrograde perfusion, concentration and flow in the hepatic vein have to be exchanged for concentration and flow in the portal vein. Values are means \pm S.E.M. of the number of experiments given in parentheses. $H A$, hepatic artery; $P V$, portal vein; $H V$, hepatic vein.

physiologic portion of about $25 \%$ for the hepatic artery and $75 \%$ for the portal vein in orthograde perfusions and a portion of about $20 \%$ for the artery and $80 \%$ for the hepatic vein in retrograde perfusions. In a second series the arterial pressure was lowered to $70 \mathrm{~cm} \mathrm{H}_{2} \mathrm{O}$ while the portal or hepatovenous pressures were maintained at their normal levels (Fig. 4). Under these conditions arterial flow was $20 \%$, and portal flow was $80 \%$ in orthograde perfusion and $15 \%$ and $85 \%$, respectively, in retrograde perfusion.

In retrograde perfusions swelling could be avoided in general. This was possible because the portal outflow in retrograde perfusions was lower by 2 to $3 \mathrm{~cm}$ than the hepatovenous outflow in orthograde perfusions, and in 

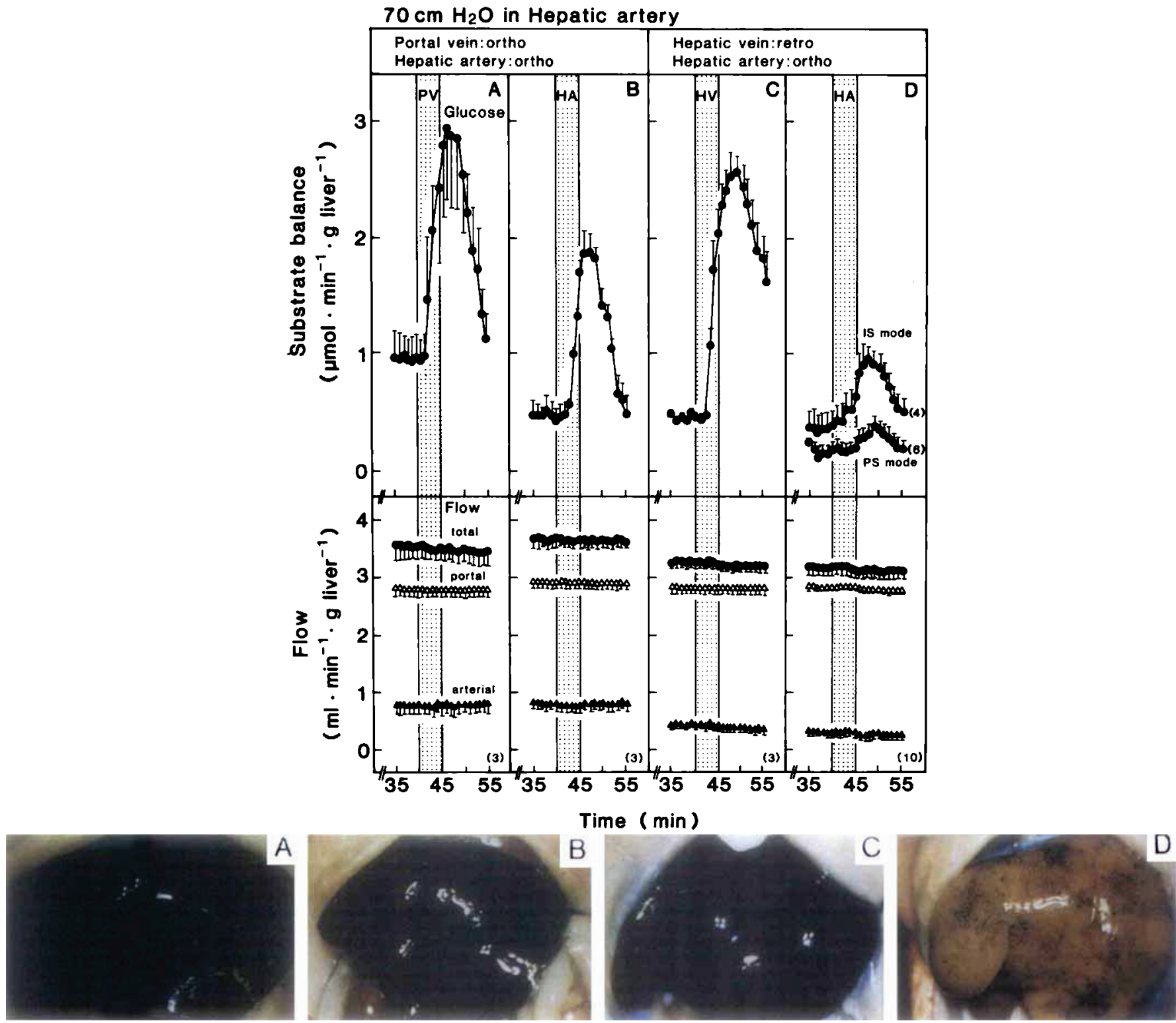

Fig. 4. Glucose balance, flow and intrahepatic distribution of trypan blue visualized at the surface after glucagon infusion in rat liver perfused through the artery at a pressure of $70 \mathrm{~cm} \mathrm{H} \mathrm{H}_{2} \mathrm{O}$ and through the portal or hepatic vein at a pressure of $18 \mathrm{~cm} \mathrm{H}_{2} \mathrm{O}$. The liver was perfused and glucagon (graphs, top) or trypan blue (photographs, bottom) were infused as described in the legend to Figure 3 . Substrate balance is defined in the legend to Figure 3. Values are means \pm S.E.M. of the number of experiments given in parentheses. $H A$, hepatic artery; $P V$, portal vein; $H V$, hepatic vein; IS mode, intrasinusoidal termination of hepatic arterioles; $P S$ mode, essentially presinusoidal termination of hepatic arterioles.

addition, the diameter of the portal catheter was large enough to prevent liver swelling. The necessity of this technical difference was to be expected because the overall hemodynamic resistance cannot be the same during orthograde and retrograde perfusions because of the asymmetry of the vascular bed of the liver: the sinusoids are narrower in the periportal zone and wider in the perivenous zone, and the terminal portal venules are smaller than the terminal hepatic venules [11]. Experiments in which liver swelling could not be avoided were discarded.
Increase in Glucose Output by Arterially Infused Glucagon During Orthograde and Retrograde Bivascular Liver Perfusion. During orthograde perfusion glucagon was infused as the first stimulus to a calculated sinusoidal concentration of $0.1 \mathrm{nmol} / \mathrm{L}$ (for definition see Materials and Methods section) through the hepatic artery or the portal vein. If the arterial pressure was 100 cm $\mathrm{H}_{2} \mathrm{O}$ or higher, arterially and portally infused glucagon increased glucose output to the same extent with the same kinetics; however, glucagon infused into either vessel did not affect arterial or portal flow (Fig. $3 \mathrm{~A}$ 
vs. B; cf. Fig. 5). If the arterial pressure was only $70 \mathrm{~cm}$ $\mathrm{H}_{2} \mathrm{O}$, arterially infused glucagon tended to elicit a slightly smaller increase in glucose output in the range of $75 \%$ (area under the curve) than portally infused glucagon (Fig. 4A vs. B; cf. Fig. 5).

These observations suggest that glucagon flowing through the artery reached the same amount of parenchyma as glucagon flowing through the portal vein, if the arterial pressure was $100 \mathrm{~cm} \mathrm{H}_{2} \mathrm{O}$, but that it reached a slightly smaller mass of parenchyma, if the arterial pressure was only $70 \mathrm{~cm} \mathrm{H}_{2} \mathrm{O}$.

During retrograde perfusion glucagon was infused also as the first stimulus to the same calculated sinusoidal concentration of $0.1 \mathrm{nmol} / \mathrm{L}$ through the hepatic artery or the vena cava and then through the hepatic vein. If the arterial pressure was $100 \mathrm{~cm} \mathrm{H}_{2} \mathrm{O}$, arterially infused glucagon caused a clearly smaller increase in glucose output in the range of 50\% (area under the curve) than hepatovenously infused glucagon (Fig. 3D vs. C; cf. Fig. 5); the enhancement by hepatovenously added glucagon was similar in amount and kinetics to the alteration by either arterially or portally infused hormone in orthograde perfusions (Fig. 3C vs. $\mathrm{A}$ and B; cf. Fig. 5). Also, in retrograde perfusions glucagon from either input site had no effect on arterial or hepatovenous flow (Fig. 3C, D). If the arterial pressure was only $70 \mathrm{~cm} \mathrm{H}_{2} \mathrm{O}$, arterially added glucagon again elicited a smaller increase in glucose release than hepatovenously infused glucagon; the increase by arterially delivered glucagon was diminished to about $30 \%$ (area under the curve) in four experiments and drastically reduced to about $10 \%$ in six experiments (Fig. 4D vs. C; cf. Fig. 5). The alterations caused by hepatovenously added glucagon in retrograde perfusions were essentially the same as those caused by portally added hormone in orthograde perfusions (Fig. $4 \mathrm{C}$ vs. A; cf. Fig. 5).

These findings indicate that in retrograde perfusions glucagon flowing through the artery reached not more than the periportal half of the parenchyma, if the arterial pressure was $100 \mathrm{H}_{2} \mathrm{O}$, and not more than between $10 \%$ and $30 \%$, if the pressure was only $70 \mathrm{~cm}$ $\mathrm{H}_{2} \mathrm{O}$.

The retrograde perfusions at reduced arterial pressure of $70 \mathrm{~cm} \mathrm{H}_{2} \mathrm{O}$ revealed that there were apparently two groups of livers, one in which the metabolic response to glucagon was still pronounced though reduced and one in which it was very weak (Fig. 4D). In the first group the artery appeared to terminate functionally within the proximal first third of the sinusoids, whereas in the second group it appeared to end at the beginning of the sinusoids (Fig. 1). However, it is possible that the difference was not due to anatomical variations. Because spontaneous constrictions of the hepatic vasculature have been observed [17], the artery terminating within the sinusoids might have been closed in about $50 \%$ of the livers studied. When the retrograde perfusions at an arterial pressure of 100 and $70 \mathrm{~cm} \mathrm{H}_{2} \mathrm{O}$ were performed in the presence of

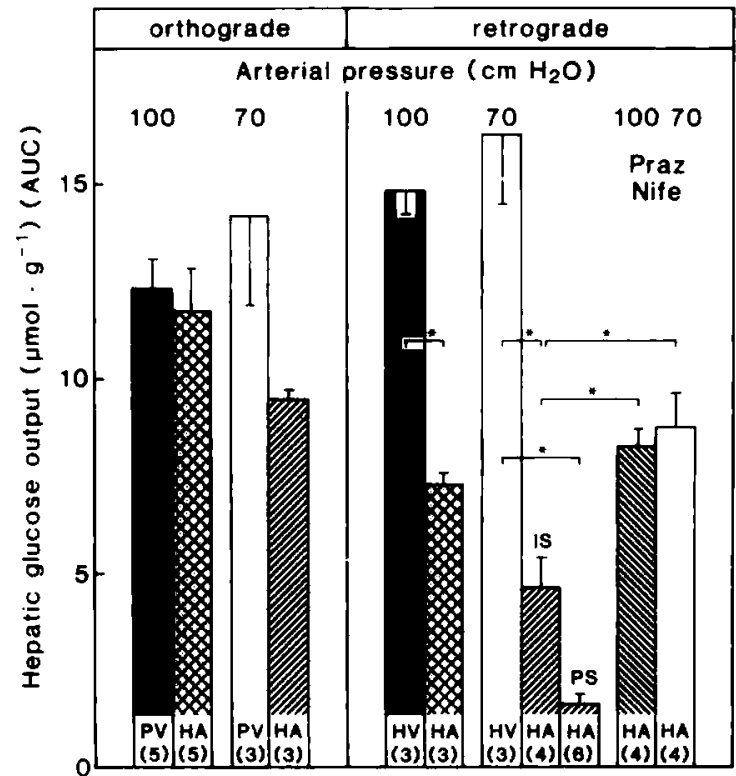

FIG. 5. Increase in glucose output after glucagon infusion in rat liver perfused through the artery and the portal or hepatic vein. The liver was perfused and glucagon was infused as described in the legends to Figures 3 and 4 . When indicated, the media contained $1 \mu \mathrm{mol} / \mathrm{L}$ prazosin (Praz) and $25 \mu \mathrm{mol} / \mathrm{L}$ nifedipine (Nife). Alterations are shown as the area under the curve (AUC). Values expressed as mean \pm S.E.M. of the number of experiments given in parentheses. Statistics: Student's $t$ test for unpaired values; * $\mathrm{p}<0.01$. IS, intrasinusoidal termination of arterioles; $P S$, essentially presinusoidal termination of arterioles (cf. Fig. 4).

$1 \mu \mathrm{mol} / \mathrm{L}$ prazosin, an $\alpha_{1}$-blocker, and $25 \mu \mathrm{mol} / \mathrm{L}$ nifedipine, a calcium antagonist, which were previously shown to prevent vasoconstriction $[2,18]$, the metabolic response to arterial glucagon was always the same, independent of the arterial pressure in the range of $50 \%$ of the maximal alterations during orthograde perfusions (Fig. 5). It thus appeared that there were no anatomic variations in the livers studied.

Intrahepatic Distribution of Arterially Supplied Trypan Blue During Orthograde and Retrograde Bivascu. lar Liver Perfusion. During orthograde perfusion trypan blue was infused through the hepatic artery or the portal vein. If the arterial pressure was $100 \mathrm{~cm} \mathrm{H}_{2} \mathrm{O}$, the dye delivered through the artery or the portal vein was distributed homogeneously within the liver tissue: the organ surface turned dark blue (Fig. 3A, B); in cross sections the whole tissue was stained equally bluish ocher, and the hepatic venules showed a darker color (Fig. 6B). If the arterial pressure was $70 \mathrm{~cm} \mathrm{H}_{2} \mathrm{O}$, only portally supplied trypan blue was distributed homogeneously; the organ surface turned dark blue (Fig. 4A). Yet arterially infused trypan blue was distributed slightly nonhomogeneously; the organ surface turned blue, leaving some brighter spots (Fig. 4B). In any case, arterially infused dye appeared in the effluent with some delay because of its transit time through the sinusoids.

Apparently, in orthograde perfusions the dye applied through the portal vein reached all regions of the liver 

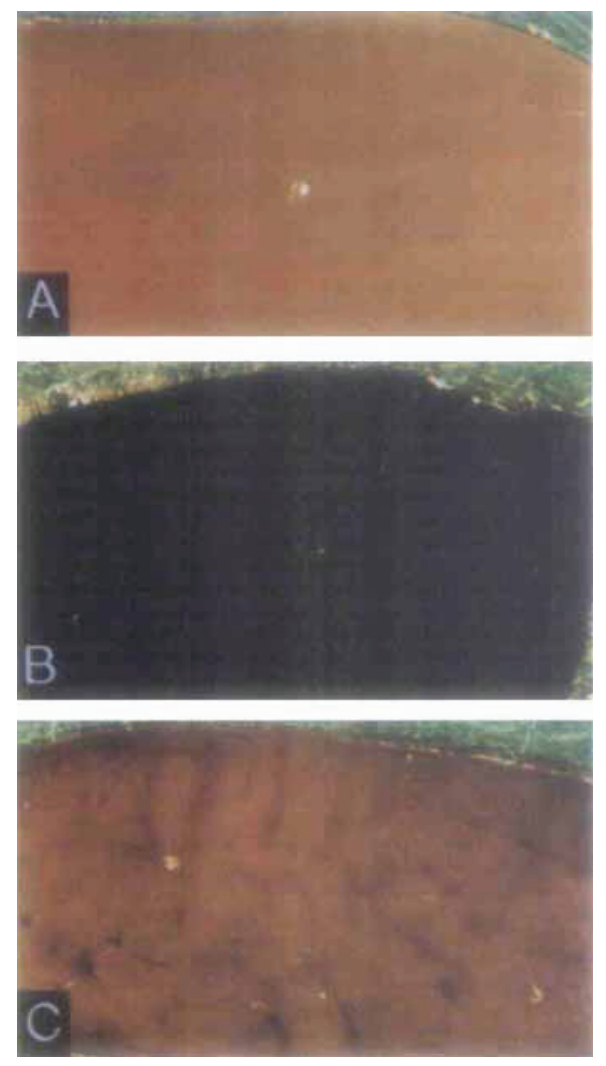

Fig. 6. Intrahepatic distribution of trypan blue visualized in cross-sections of rat liver perfused through the artery at a pressure of $100 \mathrm{~cm} \mathrm{H} \mathrm{H}_{2} \mathrm{O}$ and through the portal vein or hepatic vein, respectively, at a pressure of $18 \mathrm{~cm} \mathrm{H}_{2} \mathrm{O}$. Trypan blue was infused through the artery in orthograde (B) or retrograde (C) perfusions as described in the legend to Figure 3. Control perfusion in the orthograde direction without trypan blue (A).

equally well under all conditions studied; the dye infused through the artery reached all regions, if the arterial pressure was $100 \mathrm{~cm} \mathrm{H}_{2} \mathrm{O}$, but it reached most but not all acini, if the arterial pressure was only $70 \mathrm{~cm} \mathrm{H}_{2} \mathrm{O}$.

During retrograde bivascular liver perfusion, trypan blue was also applied through the artery or the vena cava and then through the hepatic vein. If the arterial pressure was $100 \mathrm{~cm} \mathrm{H}_{2} \mathrm{O}$, hepatovenously supplied trypan blue was distributed homogeneously; the organ surface turned dark blue (Fig. 3C). Yet arterially infused trypan blue was not distributed homogeneously in the liver tissue. The organ surface did not turn dark blue but only showed light blue spots scattered almost homogeneously (Fig. 3D); in cross sections the greatest part of the tissue remained unstained, and only the peribiliary arteries and the portal venules together with the proximal periportal tissue showed a bluish red color (Fig. 6C). If the arterial pressure was $70 \mathrm{~cm} \mathrm{H}_{2} \mathrm{O}$, hepatovenously applied trypan blue was distributed again homogeneously; the organ surface turned dark blue (Fig. 4C). Yet arterially applied trypan blue in some cases was distributed nonhomogenously in the liver tissue, but in most cases it did not reach the tissue at all; the liver did not turn dark blue but showed more (not shown) or less light blue spots scattered over the organ (Fig. 4D). In any case, arterially applied dye reached the effluent almost without delay because of the lack of an appreciable transit time through the sinusoids.

Apparently, in retrograde perfusions the hepatovenously applied dye reached all regions of the liver under all conditions studied; the arterially infused dye reached almost all acini in their proximal parts, if the arterial pressure was $100 \mathrm{~cm} \mathrm{H}_{2} \mathrm{O}$, but only some or very few sinusoids, thus remaining within the vascular tree, if the arterial pressure was $70 \mathrm{~cm} \mathrm{H}_{2} \mathrm{O}$.

Uptake of Arterially Supplied Acridine Orange During Orthograde and Retrograde Bivascular Liver Perfusion. During orthograde perfusion with an arterial pressure of $100 \mathrm{~cm} \mathrm{H} \mathrm{H}_{2} \mathrm{O}$, acridine orange was infused through the hepatic artery or the portal vein. The proximal one half to two thirds of the liver acinus (i.e., more than the periportal zone) was labeled by portal application (Fig. 7A). The distal half or third was not labeled, because acridine was taken up so efficiently by the upstream cells as observed previously [16]. The same labeling was observed after arterial application; yet the areas labeled were slightly smaller than those labeled by portal application (Fig. 7B vs. A). In no case of arterial application was an area around the terminal portal vein unlabeled and a more distal zone of the same acinus labeled (Fig. 7B). This indicates that the terminal arterioles do not mix only at sites within the distal two thirds of the sinusoids (Fig. 1, middle) but always at the beginning and also within the first third of the sinusoids (Fig. 1, right). Apparently, in orthograde perfusions acridine orange applied through the artery reached all sinusoids, also entering always at their beginning and never only within their final two thirds.

During retrograde perfusion with an arterial pressure of $100 \mathrm{~cm} \mathrm{H}_{2} \mathrm{O}$, acridine orange was also infused through the hepatic artery or the vena cava and then through the hepatic vein. The distal half to two thirds of the liver acinus (i.e., more than the perivenous zone) was labeled by the hepatovenous application (Fig. 7C). Yet only three or four proximal periportal cell layers were labeled by arterial application (Fig. 7D). Clearly, in retrograde perfusions acridine orange applied through the artery entered all sinusoids within their first third.

\section{DISCUSSION}

Presinusoidal and Intrasinusoidal Confluence of the Hepatic Artery and Portal Vein. It was demonstrated in this study with rat liver perfused simultaneously through the artery and through either the portal vein in the orthograde direction or the hepatic vein in the retrograde direction that (1) glucagon infused through the artery caused an increase in glucose output not only in orthograde perfusions but also, to a clearly lesser extent, in retrograde perfusions (Fig. 3B vs. D), (2) trypan blue supplied through the artery reached all regions of the liver in orthograde perfusions and only the periportal parts of all regions in retrograde perfusions (Fig. 3B vs. D; Fig. 6) and (3) acridine orange applied 

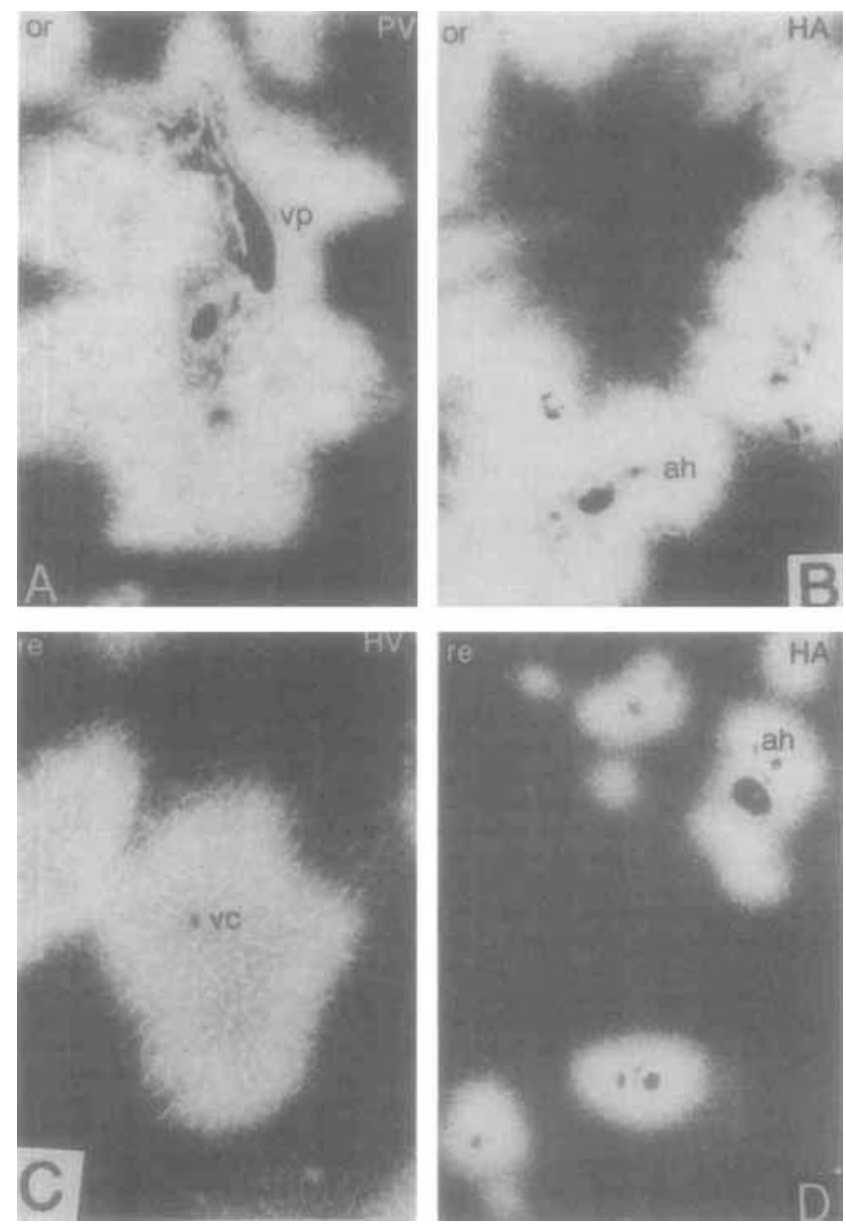

FIG. 7. Zonal uptake of infused acridine orange in rat liver perfused through the artery at a pressure of $100 \mathrm{~cm} \mathrm{H}_{2} \mathrm{O}$ and through the portal or hepatic vein at a pressure of $18 \mathrm{~cm} \mathrm{H}, O$. The liver was perfused and acridine orange was infused for 5 min through the artery, the portal vein or the hepatic vein, as indicated, to a final calculated sinusoidal concentration of $120 \mu \mathrm{mol} / \mathrm{L}$. Or, orthograde perfusion; re, retrograde perfusion; $P V$, portal vein; $H A$, hepatic artery; $H V$, hepatic vein; $A h$, arteria hepatica; $v p$, vena portae; $v c$, vena centralis.

through the artery was taken up by one half or two thirds of the cell layers beginning from the terminal portal venule in orthograde perfusions and also by three or four cell layers in the periportal portion of the sinusoids in retrograde perfusions (Fig. 7B vs. D). These findings allow the conclusion that in rat liver the confluence of the terminal hepatic artery and the portal vein occurs at a presinusoidal site and a proximal intrasinusoidal site (Fig. 1, right).

For the interpretation of the metabolic responses to glucagon, it is assumed first that all periportal or perivenous hepatocytes showed the same reactivity toward glucagon and that only those hepatocytes that had direct contact with glucagon responded. Then it is assumed that the arterioles are not leaky; that is, they do not allow the penetration of glucagon until they empty into the terminal portal vein or the sinusoids. The finding that arterial glucagon caused an increase in glucose output in retrograde perfusions, which was about $50 \%$ of that in orthograde perfusions (Fig. 3D vs. B), would indicate that the arterioles enter the sinusoids in their middle. However, the finding that arterial acridine orange was taken up by only three to four proximal cell layers in retrograde perfusions (Fig. 7D) would indicate that the arterioles enter the sinusoids in their proximal fifth or fourth. This latter proposal is straightforward, whereas the former is indirect, on the basis of the above assumptions, which may not be correct.

Several arguments for the interpretation of metabolic responses to glucagon should be considered. (a) According to the model of metabolic zonation, the periportal hepatocytes release and the perivenous hepatocytes take up glucose [19-22]. Thus the proximal periportal hepatocytes might have responded to glucagon with a higher release of glucose than the distal periportal cells or even the perivenous cells. (b) Because hepatocytes are linked by gap junctions, cells that were not in direct contact with glucagon might have also responded. When arguments (1) and (2) are considered, it can be concluded that the hepatic arterioles terminate not only in portal venules before the beginning of the 
sinusoids, where a resistance $R_{1}$ has to be overcome, but also in the first third of the sinusoids, where a resistance $\mathrm{R}_{2}$ has to be surmounted (Fig. 1, right). $\mathrm{R}_{2}$ appeared to be greater than $R_{1}$, which would explain why fewer intrasinusoidal confluence sites were kept open, when the arterial pressure was below normal (i.e., $70 \mathrm{~cm} \mathrm{H}_{2} \mathrm{O}$ instead of $100 \mathrm{~cm} \mathrm{H}_{2} \mathrm{O}$ ) (Fig. 4D vs. Fig. 3D). (c) Until the arterioles coalesce with the terminal portal veins, they still have a continuous endothelium, which does not allow the simple diffusion of glucagon into the parenchyma but which may allow the unspecific transcellular transport of glucagon through vesicles or channels formed from vesicles. If this transport were very active, which is doubtful, the metabolic responses to arterial glucagon in retrograde perfusions (Figs. 3D and 4D) might also be explained by hormone penetration into the parenchyma from an artery with a presinusoidal confluence (Fig. 1, left). (d) Finally, there may have been some backflow into the sinusoids, if the pressure after the arterial presinusoidal resistance site (Fig. 1, left) exceeded the sinusoidal pressure. However, prazosin and nifedipine increased the actions of arterial glucagon to identical values in retrograde perfusions with high and low arterial pressure (Fig. 5). A nonspecific transendothelial transport should not be affected by vasorelaxants. A backflow after vasorelaxation should be greater, the higher the arterial pressure; this was not the case (Fig. 5). Thus these findings indicate that arterial glucagon in retrograde perfusions reached the parenchyma by means of convection through a true resistance site $\left(R_{2}\right.$ in Fig. 1, right $)$ and not by means of nonspecific transendothelial transport or backflow.

Comparison of Anatomic and Biochemical Studies on the Hepatic Microcirculation. Anatomical studies [3-12] with different species such as rat [5, 6, 9, 11, 12], mouse [12], hamster [9], rabbit [10, 12], frog [12], pig $[11,13]$ or human beings $[9,11]$ have led to the controversial results of either a predominantly presinusoidal $[5,9]$ or a mainly intrasinusoidal $[6-8,11-13]$ site of confluence of the hepatic artery and the portal vein (Fig. 1). Some controversies may be due to species differences [9], but most remain unexplained.

The present biochemical study with the isolated perfused rat liver showing a presinusoidal and proximal intrasinusoidal site of confluence is in line with two previous functional investigations with cat liver in vivo $[23,24]$. Arterially and portally applied cholyltaurine caused the same stimulation of bile flow [23], and arterially and portally administered indocyanine green was extracted equally well [24]. Thus at least in rat and cat liver the parenchymal cells can be considered to be supplied by a well mixed combination of arterial and portal inflows.

Comparison of Monovascular Portal Perfusion with Bivascular Arterial and Portal Perfusion of Isolated Liver. Substrate handling and the actions of circulating hormones can be expected to be independent from the site of entry, if portal and arterial blood mix only before entering the sinusoids supplying the tissue (Fig. 1, left) and if substrates and hormones would not stimulate additional production of local hormones during their passage through either the arterial or portal bed. The portal liver perfusion could then still be regarded as an adequate experimental model.

Yet substrate handling and hormone actions may well be dependent on the site of entry, if arterial and portal blood mix not only at presinusoidal sites but also at intrasinusoidal sites (Fig. 1, right) and if substrates and hormones would initiate the production of local hormones specific for either the arterial or portal bed. Also, the liver might be able to sense the physiological concentration gradients falling from the portal vein to the hepatic artery, for example, the concentration gradients of glucose and insulin after a meal $[1,25]$. Moreover, some hormones such as epinephrine and norepinephrine cause hemodynamic effects not only in their inflow vessel (e.g., the artery) but also in the corresponding contralateral vessel (e.g., the portal vein) [26-28], which in turn might influence the metabolic actions. Finally, acetylcholine appears to influence liver metabolism only when infused through the artery [29]. In these cases only the arterial and portal liver perfusion can be regarded as an adequate experimental model.

Acknowledgment: We thank Hannelore Beck, Silvia Hesse, Annegret Nath, Helga Herbort and Regina Engelhardt for their excellent technical assistance during different stages of this study.

\section{REFERENCES}

1. Gardemann A, Strulik H, Jungermann K. A portal-arterial glucose concentration gradient as a signal for an insulin-dependent net glucose uptake in perfused rat liver. FEBS Lett 1986;202:255-259.

2. Gardemann A, Strulik H, Jungermann K. Nervous control of glycogenolysis and blood flow in arterially and portally perfused liver. Am J Physiol 1987;253:E238-E245.

3. Elias $\mathrm{H}$. A re-examination of the structure of the mammalian liver. II. The hepatic lobule and its relation to the vascular and biliary systems. Am J Anat 1949;85:379-456.

4. Warwick R, Williams PL. Gray's anatomy. 35th ed. Edinburgh: Longman, 1973:1309-1310.

5. Hase T, Brim J. Observations on the microcirculatory architecture of the rat liver. Anat Rec 1966;156:157-174.

6. Kardon RR, Kessel RG. Three-dimensional organization of the hepatic microcirculation in the rodent as observed by scanning electron microscopy of corrosion casts. Gastroenterology 1980;79: $72-81$.

7. Kessel RG, Kardon RH. Tissues and organs, a text-atlas of scanning electron microscopy. San Francisco: Freeman, 1979:188.

8. Motta P, Muto M, Fujita T, Die Leber, Rasterelektronenmikroskopischer Atlas. Stuttgart: Schattauer, 1980:130-143.

9. Yamamoto K, Sherman I, Phillips MJ, Fisher MM. Threedimensional observations of the hepatic arterial terminations in rat, hamster and human liver by scanning electron microscopy of microvascular casts. HEPATOLOGY 1985;5:452-456.

10. Reeves JT, Leathers JE, Boatright C. Microradiography of the rabbit's hepatic microcirculation. The similarity of the hepatic portal and pulmonary arterial circulations. Anat Rec 1966;154: 103-120.

11. Rappaport AM. The microcirculatory acinar concept of normal and pathological hepatic structure. Beitr Pathol 1976;157:215-243.

12. McCuskey RS. A dynamic and static study of the hepatic sphincters. Am J Anat 1966;119:455-478.

13. Kaman J. Zur terminalen Ramifikation der Arteria hepatica des Schweins (On the terminal ramification of the arteria hepatica of the pig). Mikroskopie 1965;20:129-140.

14. Banauch D, Brümmer W, Ebeleing W, Metz H, Rendrey H, 
Leybold K, Rick W. Eine Glucose-Dehydrogenase für die GlucoseBestimmung in Körperflüssigkeiten (A glucose dehydrogenase for the determination of glucose in body fluids). Z Klin Chem Klin Biochem 1975;13:101-107.

15. Ji S, Beckh K, Jungermann K. Regulation of oxygen consumption and microcirculation by $\alpha$-sympathetic nerves in isolated perfused rat liver. FEBS Lett 1984;167:117-122

16. Gumucio JJ, Miller DL, Kraus MD, Cutter-Zanolli C. Transport of fluorescent compounds into hepatocytes and the resultant zonal labeling of the hepatic acinus in the rat. Gastroenterology 1981;80:639-646.

17. Daniel PM, Prichard MML. Variations in the circulation of the portal venous blood within the liver. J Physiol 1951;114:521-537.

18. Athari A, Jungermann $\mathrm{K}$. Role of extracellular calcium in the metabolic and hemodynamic actions of sympathetic nerve stimulation, noradrenaline and prostaglandin $\mathbf{F}_{2 \alpha}$ in perfused rat liver Differential inhibition by nifedipine and verapamil. Biochem Int 1990;20:13-23.

19. Jungermann K. Metabolic zonation of liver parenchyma. Semin Liver Dis 1988;8:329-342.

20. Jungermann K, Katz N. Functional specialization of different hepatocyte populations. Physiol Rev 1989;69:708-764.

21. Gumucio JJ. Hepatocyte heterogeneity: the coming of age from the description of a biological curiosity to a partial understanding of its physiological meaning and regulation. HEPAYOLOGY 1989:9: 154-160.
22. Traber PG, Chianale J, Gumucio JJ. Physiologic significance and regulation of hepatocellular heterogeneity. Gastroenterology 1988;95:1130-1143.

23. Lautt WW, Daniels TR. Differential effect of taurocholic acid on hepatic arterial resistance vessels and bile flow. Am J Physiol 1983;244:G366-G369.

24. Lautt WW, Legare DJ, Daniels TR. The comparative effects of administration of substances via the hepatic artery or portal vein on hepatic arterial resistance, liver blood volume and hepatic extraction in cats. HEPATOLOGY 1984;4:927-932

25. Adkins BA, Myers SR, Hendrick GK, Stevenson RW, Williams PE, Cherrington $\mathrm{AD}$. Importance of the route of intravenous glucose delivery to hepatic glucose balance in the conscious dog. $\mathrm{J}$ Clin Invest 1987;79:557-565.

26. Richardson PDI, Withrington PG. Physiological regulation of the hepatic circulation. Ann Rev Physiol 1982;44:57-69

27. Gardemann A, Jahns U, Jungermann K. Control of glycogenolysis and blood flow by arterial and portal noradrenaline in perfused rat liver. Am J Physiol 1991;260:E762-E771.

28. Meyerholz HH, Gardemann A, Jungermann K. Control of glycogenolysis and blood flow by arterial and portal adrenaline in perfused rat liver. Biochem J 1991;276:609-616.

29. Gardemann A, Beck H, Jungermann K. Control of glycogenolysis and flow by arterial and portal acetylcholine in perfused rat liver. Biochem J 1990;271:599-604. 